\title{
A prospective study comparing 5-year results between superobese and non-superobese patients after laparoscopic adjustable gastric banding
}

\author{
Zygimantas Juodeikis, Vilma Brimienè, Gintautas Brimas \\ Clinic of Gastroenterology, Nephrourology and Surgery, Institute of Clinical Medicine, Vilnius University, Vilnius, Lithuania
}

Videosurgery Miniinv 2019; 14 (1): 79-85

DOI: https://doi.org/10.5114/wiitm.2018.77269

\begin{abstract}
Introduction: Laparoscopic adjustable gastric banding (LAGB) is considered to be the least invasive, reversible, and the safest bariatric operation regarding mortality and morbidity, and its application to high-risk superobese (SO) individuals seems rational.

Aim: There are differing viewpoints regarding the effectiveness of $L A G B$ in superobese $\left(B M I>50 \mathrm{~kg} / \mathrm{m}^{2}\right)$ patients. The aim of this study was to compare the safety and efficacy of LAGB in SO and non-superobese (NSO) patients in the long term (> 5 years).

Material and methods: We undertook a prospective single-center study to compare the safety and efficacy of $L A G B$ in SO and NSO patients after 5 years. One hundred and three morbidly obese patients underwent LAGB in the period from January 2009 to January 2010. Sixty-four of the patients were NSO and 39 SO. After 5 years, we evaluated their weight loss, comorbidities, complications, and quality of life.

Results: A total of 90 of 103 patients (87.3\%) completed the 5-year follow-up. The percentage excess weight loss was $50.4 \%$ in the NSO and $38.8 \%$ in the SO group $(p=0.072)$. The proportion of patients who lost > 50\% excess weight was significantly larger in the NSO group $(p=0.045)$. There were significantly more patients in the NSO group whose metabolic syndrome had resolved $(p<0.001)$. There were no differences regarding the resolution of other comorbidities and postoperative complications.

Conclusions: This study suggests that LAGB can lead to substantial and long-lasting weight loss after 5 years. Our study found that SO patients demonstrate inferior weight loss results, and lower overall BAROS scores; thus we do not support the primary use of LAGB in SO patients.
\end{abstract}

Key words: bariatric surgery, laparoscopic adjustable gastric banding, super-obesity.

\section{Introduction}

Laparoscopic adjustable gastric banding (LAGB) is a bariatric procedure with a history of more than 30 years. The popularity of LAGB has recently decreased. At its peak, it was the most popular bariatric procedure worldwide, while in 2013 the number of LAGB operations dropped to $10 \%$ [1]. This trend is mainly caused by a high number of band compli- cations in the long term and the rising popularity of sleeve gastrectomy [2].

In tandem with a rising rate of morbidly obese individuals globally, there is also a rising prevalence of superobesity (body mass index (BMI) >50 kg/ $\mathrm{m}^{2}$ ). Although bariatric surgery is the only treatment modality that can dramatically reduce the body weight and improve obesity-related comorbidities in superobese (SO) individuals, the optimal

\section{Address for correspondence}

Zygimantas Juodeikis PhD, Clinic of Gastroenterology, Nephrourology and Surgery, Institute of Clinical Medicine, Vilnius University,

29 Šiltnamių St, LT-04130 Vilnius, Lithuania, phone: +370 69986915, e-mail: z.juodeikis@gmail.com 
surgical strategy is still in dispute. Some studies have shown that superobesity is associated with poor weight loss results and higher morbidity after bariatric surgery $[3,4]$. The use of LAGB in the SO population is also controversial. Although some studies have demonstrated excellent weight loss results [5-7], there are studies that have found that the application of LAGB in SO individuals is associated with weight loss failure and a high incidence of gastric band removal [8].

Since LAGB is considered to be the least invasive, and safest bariatric operation, regarding mortality and morbidity in the early postoperative period, its application to high-risk SO individuals seems rational.

\section{Aim}

The aim of this study was to compare the safety and efficacy of LAGB in SO and non-SO (NSO) patients in the long term ( $>5$ years).

\section{Material and methods}

The study was reviewed and approved by the Lithuanian bioethics committee. All patients seeking bariatric surgery were invited to participate in the study. Patients were eligible if they were aged between 18 and 70 years, with a BMI of more than $40 \mathrm{~kg} / \mathrm{m}^{2}$, or a BMI of $35-40 \mathrm{~kg} / \mathrm{m}^{2}$ with obesity-related comorbidities. Candidates were excluded if they had a history of previous bariatric surgery or were pregnant, or had other contraindications for laparoscopic surgery. Between January 1, 2009 and January 31, 2010, 103 morbidly obese patients (64 NSO and 39 SO patients) underwent LAGB at the Vilnius University Hospital 'Santariškių Klinikos'. All patients underwent a standard LAGB using the pars flaccida technique, which has been described previously [9]. A single surgeon performed all of the operations.

Early mobilization was started 3-4 $\mathrm{h}$ after the operation. Oral liquids were started on postoperative day one. All patients were discharged on the first postoperative day, as soon as oral fluid was tolerated and pain controlled by oral analgesics. The first band adjustments were scheduled 4 weeks postoperatively, when patients had returned to a normal diet. Further band adjustments were dependent on individual weight loss results. The patients were asked to come for band adjustment in cases of discontinuance of weight loss for more than 2 weeks, but not earlier than 4 weeks after the previous adjustment. A complete multidisciplinary evaluation was performed at 1, 3, and 5 years postoperatively.

The primary endpoint was weight loss, and the secondary endpoints were postoperative morbidity, mortality, improvement of comorbidities, and quality of life.

A multidisciplinary team, consisting of an endocrinologist, gastroenterologist, dietitian, cardiologist, and bariatric surgeon, performed the preoperative patient evaluation.

Assessed comorbidities consisted of diabetes mellitus (DM), arterial hypertension (AHT), cardiovascular diseases (CVD), dyslipidemia, metabolic syndrome (MS), gastroesophageal reflux disease (GERD), and degenerative joint disease (DJD). Comorbidities were assessed based on information given by the patients, clinical examination, and blood samples obtained after an overnight fast. Moreover, all patients underwent upper gastrointestinal endoscopy, abdominal sonography, and upper gastrointestinal tract radiography.

The resolution and improvement criteria of the comorbidities were adapted according to the Bariatric Analysis and Reporting Outcome System (BAROS) [10].

Diabetes mellitus was defined as either a fasting plasma glucose of $\geq 7.1 \mathrm{mmol} / \mathrm{l}$, glycated hemoglobin $\left(\mathrm{HbA}_{1 \mathrm{c}}\right) \geq 6.5 \%$, or the use of antidiabetic medication [11]. Arterial hypertension, dyslipidemia and MS were diagnosed according to the Adult Treatment Panel III guidelines [12]. Diagnosis of CVD was based on previously documented evidence of coronary artery disease, peripheral vascular disease, or congestive heart failure. Gastroesophageal reflux disease was diagnosed by upper gastrointestinal endoscopy, self-reported symptoms, and the use of anti-reflux medication. Degenerative joint disease was diagnosed based on self-reported symptoms and previously documented radiographic studies.

Quality of life was estimated using a modified Moorehead-Ardelt quality of life (M-AQoL) questionnaire, which evaluates self-esteem, physical well-being, social relationships, work, sexuality, and eating behavior [13]. The evaluations of the M-AQoL questionnaire scores range from -3 (very poor quality of life) to +3 (very good quality of life). Changes in obstructive sleep apnea and infertility were not included in the final score because there was no possibility of conducting polysomnography and hormonal studies, as suggested by the BAROS. 


\section{Statistical analysis}

Statistical analysis was performed using SPSS version 21.0 (SPSS Inc., Chicago). Pearson's $\chi^{2}$ or Fisher's exact test was used to test for differences in categorical variables, and the $t$-test or Mann-Whitney 2-sample test for continuous variables was used, depending on the distribution. $P$-values $<0.05$ were considered statistically significant.

\section{Results}

A total of 103 (64 NSO and 39 SO) morbidly obese patients underwent LAGB (Figure 1). The mean patient age at the time of surgery in both groups was 45.9 years (range: $21-70$ ). Among the patients, 69 (67\%) were women and 34 (33\%) were men. The mean preoperative $\mathrm{BMI}$ was $47.5 \mathrm{~kg} / \mathrm{m}^{2}$ (range: 35-68). The baseline characteristics are presented in Table I. A total of 90 out of 103 (87.3\%) patients completed the 5-year follow-up: 4 (3.8\%) patients died, $6(5.8 \%)$ had their bands removed, and $3(2.9 \%)$ patients were unable to attend. One death was caused by lung cancer, and the remaining died because of acute cardiovascular events (1-4 years postoperatively). Patients whose bands had to be removed were excluded from further weight loss analysis.

The body mass changes of NSO and SO patients at 5 years are depicted in Table II. The mean \% excess weight loss (\%EWL) after 5 years was $47.3 \%$. The \%EWL > 50\% was observed in 37 (41.1\%) patients. The proportion of patients who lost $>50 \%$ excess weight was significantly greater in the NSO group $(p=0.045)$. There was also a significantly greater proportion of patients who reached a BMI of $<35 \mathrm{~kg} / \mathrm{m}^{2}$ in the NSO group $(p=0.011)$.

The preoperative distribution of comorbidities is shown in Table III. There were significantly more patients with MS in the SO group. Five years after LAGB, resolution or improvement of type 2 diabetes was observed in 14 (42.4\%) of the patients, and $\mathrm{AHT}$, CVD, dyslipidemia, GERD, and DJD had improved or resolved in 35 (39\%), 7 (33.3\%), 44 (63.7\%), $21(46.6 \%)$, and $24(33.8 \%)$ of the patients, respectively (Table IV). Five years following LAGB, only

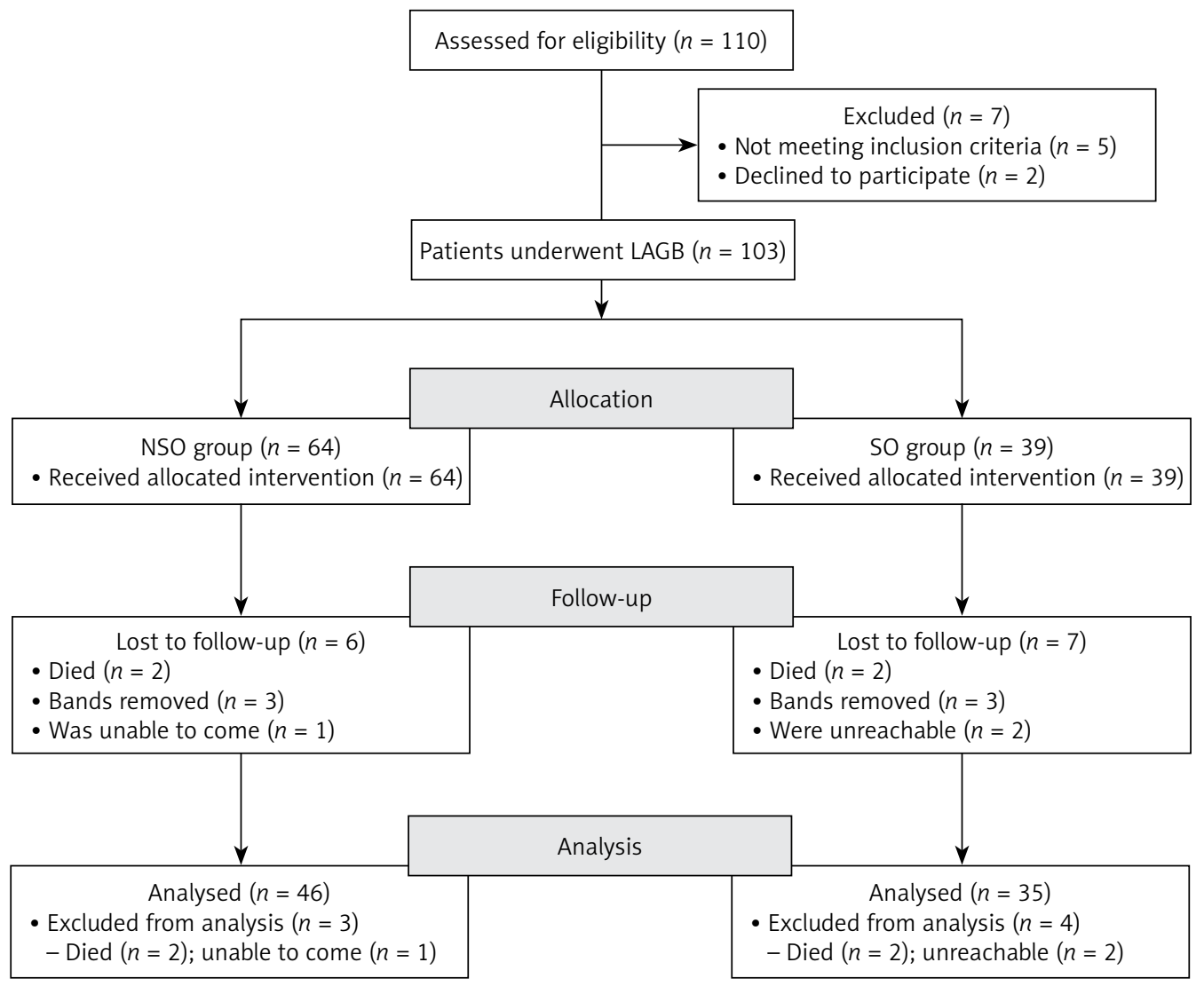

Figure 1. Study flow chart 
Table I. Baseline characteristics

\begin{tabular}{|lcccc|}
\hline Parameter & All patients & BMl $<50 \mathrm{~kg} / \mathrm{m}^{2}$ & BMI $\geq 50 \mathrm{~kg} / \mathrm{m}^{2}$ & $P$-value \\
\hline Patients & 103 & 64 & 39 & NS \\
\hline Age [years] & $45.9 \pm 11.7$ & $44.8 \pm 12.2$ & $47.7 \pm 10.6$ & NS \\
\hline \begin{tabular}{l} 
Gender, $n(\%):$ \\
\hline Female
\end{tabular} & $69(67)$ & $44(68.8)$ & $25(64.1)$ & NS \\
\hline Male & $34(33)$ & $20(31.2)$ & $14(35.9)$ & NS \\
\hline Body weight $[\mathrm{kg}]$ & $137.6 \pm 24.4$ & $125.3 \pm 18.0$ & $157.8 \pm 19.4$ & $<0.001$ \\
\hline BMI $\left[\mathrm{kg} / \mathrm{m}^{2}\right]$ & $47.5 \pm 7.3$ & $42.7 \pm 3.9$ & $35.3 \pm 4.3$ & $<0.001$ \\
\hline EBMI $\left[\mathrm{kg} / \mathrm{m}^{2}\right]$ & $22.5 \pm 7.4$ & $17.7 \pm 3.9$ & $30.3 \pm 4.3$ & $<0.001$ \\
\hline
\end{tabular}

NS - non-significant, $B M I$ - body mass index, EBMI - excess BMI.

Table II. Body mass changes after 5 years

\begin{tabular}{|lcccc|}
\hline Weight variable & All patients & BMI $<50$ & BMI $\geq 50$ & $P$-value \\
\hline WL $[\mathrm{kg}]$ & $28.8 \pm 18.3$ & $25.4 \pm 15.5$ & $32.3 \pm 22.6$ & 0.085 \\
\hline BMIL $\left[\mathrm{kg} / \mathrm{m}^{2}\right]$ & $10.1 \pm 6.7$ & $8.7 \pm 5.5$ & $11.7 \pm 8.3$ & 0.069 \\
\hline$\% T W L$ & $21.2 \pm 13.2$ & $20.4 \pm 12.2$ & $21.1 \pm 15.4$ & 0.807 \\
\hline$\% E W L$ & $47.3 \pm 29.7$ & $50.4 \pm 29.8$ & $38.8 \pm 29.1$ & 0.072 \\
\hline BMI < 35, $n(\%)$ & $38(40.4)$ & $33(55)$ & $5(14.7)$ & $<0.001$ \\
\hline$\% E W L>50 \%, n(\%)$ & $37(35.9)$ & $28(46.6)$ & $9(27.2)$ & 0.045 \\
\hline
\end{tabular}

WL - weight loss, BMIL - body mass index loss, TWL - total weight loss, \%EWL - percentage excess weight loss.

Table III. Comorbidities at baseline

\begin{tabular}{|c|c|c|c|c|}
\hline Comorbidities & Total, $n$ (\%) & $\begin{array}{c}\mathrm{BMI}<50 \mathrm{~kg} / \mathrm{m}^{2} \\
n(\%)\end{array}$ & $\begin{array}{c}\mathrm{BMI} \geq 50 \mathrm{~kg} / \mathrm{m}^{2} \\
n(\%)\end{array}$ & $P$-value \\
\hline DM & $36(34.9)$ & 19 (29.6) & $17(43.5)$ & 0.094 \\
\hline AHT & $82(79.6)$ & 46 (71.9) & $36(92.3)$ & 0.013 \\
\hline CVD & $21(20.3)$ & $8(12.5)$ & $13(33.3)$ & 0.022 \\
\hline Dyslipidemia & $69(66.9)$ & $42(65.6)$ & $27(69.2)$ & 0.831 \\
\hline MS & $69(66.9)$ & $37(57.8)$ & $32(82.1)$ & 0.012 \\
\hline GERD & $45(43.6)$ & 25 (39.1) & $20(51.3)$ & 0.306 \\
\hline DJD & $71(68.9)$ & $40(62.5)$ & $31(79.5)$ & 0.082 \\
\hline
\end{tabular}

DM - diabetes mellitus, AHT - arterial hypertension, CVD - cardiovascular disease, MS - metabolic syndrome, GERD - gastroesophageal reflux disease, $D J D$ - degenerative joint diseases.

41 out of 69 patients who had MS before the operation met the MS criteria. There were significantly more patients in the NSO group whose MS had resolved $-24(64.8 \%)$ vs. $4(12.5 \%)(p<0.001)$.

The overall complication rate at 5 years was $14.5 \%$. Complications consisted of 5 band erosions, 4 port-related complications, 3 band slippages, and
3 band intolerances (Table V). Port-related complications consisted of 3 port-site infections and 1 port inversion. None of the port-site infections were related to band erosion. There were no significant differences between the NSO and SO groups. Thirteen complications were managed surgically. Six bands were removed, 3 in the NSO group and 
Table IV. Resolution and improvement of comorbidities at 5 years

\begin{tabular}{|c|c|c|c|c|c|c|c|c|}
\hline \multirow[t]{2}{*}{ Comorbidities } & \multicolumn{4}{|c|}{ Resolution } & \multicolumn{4}{|c|}{ Improvement } \\
\hline & $\begin{array}{l}\text { Total } \\
n(\%)\end{array}$ & $\begin{array}{c}\text { BMI } \\
<50 \mathrm{~kg} / \mathrm{m}^{2} \\
n(\%)\end{array}$ & $\begin{array}{c}\text { BMI } \\
\geq 50 \mathrm{~kg} / \mathrm{m}^{2} \\
n(\%)\end{array}$ & $P$-value & $\begin{array}{l}\text { Total } \\
n(\%)\end{array}$ & $\begin{array}{c}\text { BMI } \\
<50 \mathrm{~kg} / \mathrm{m}^{2} \\
n(\%)\end{array}$ & $\begin{array}{c}\text { BMI } \\
\geq 50 \mathrm{~kg} / \mathrm{m}^{2} \\
n(\%)\end{array}$ & $P$-value \\
\hline $\mathrm{DM}$ & $5(15.1)$ & $4(23.5)$ & $1(6.2)$ & 0.33 & $9(27.2)$ & $5(29.4)$ & $4(25)$ & 0.89 \\
\hline AHT & $12(14.6)$ & $8(17.3)$ & $4(11.1)$ & 0.74 & $23(28)$ & $13(28.2)$ & $10(27.7)$ & 0.79 \\
\hline CVD & $1(4.7)$ & $1(12.5)$ & $0(0)$ & 0.42 & $6(28.5)$ & $2(25)$ & $4(30.7)$ & 0.62 \\
\hline DYS & $44(63.7)$ & $29(69)$ & $15(55.5)$ & 0.73 & - & - & - & - \\
\hline MS & $28(40.5)$ & $24(64.8)$ & $4(12.5)$ & $<0.001$ & - & - & - & - \\
\hline GERD & $12(26.6)$ & $10(40)$ & $2(10)$ & 0.065 & $9(20)$ & $1(4)$ & $8(40)$ & $<0.001$ \\
\hline DJD & $10(14)$ & $8(20)$ & $2(6.4)$ & 0.29 & 14 (19.7) & $9(22.5)$ & $5(16.1)$ & 0.89 \\
\hline
\end{tabular}

DM - diabetes mellitus, AHT - arterial hypertension, CVD - cardiovascular disease, DYS - dyslipidemia, MS - metabolic syndrome, GERD - gastroesophageal reflux disease, DJD - degenerative joint diseases.

Table V. Complications 5 years after LAGB

\begin{tabular}{|lcccc|}
\hline Adverse event & $\begin{array}{c}\text { Total } \\
n(\%)\end{array}$ & BMI $\begin{array}{c}50 \mathrm{~kg} / \mathrm{m}^{2} \\
n(\%)\end{array}$ & $\begin{array}{c}\text { BMI } \geq 50 \mathrm{~kg} / \mathrm{m}^{2} \\
n(\%)\end{array}$ \\
\hline Band erosion & $5(4.8)$ & $4(6.2)$ & $1(2.5)$ & $2(5.1)$ \\
\hline Band slippage & $3(2.9)$ & $1(1.5)$ & $2(5.1)$ & 0.647 \\
\hline Intolerance & $3(2.9)$ & $1(1.5)$ & $2(5.1)$ & 0.555 \\
\hline Port related & $4(3.8)$ & $2(3.1)$ & $7(17.9)$ & 0.632 \\
\hline Total & $15(14.5)$ & $8(12.5)$ & 0.566 \\
\hline
\end{tabular}

3 in the SO group ( $p=0.67), 3$ bands due to erosions and 3 due to the psychological intolerance of the patient and insufficient weight loss. All 3 band slippages were managed by laparoscopic band repositioning.

At baseline, the average M-AQoL questionnaire scores were significantly higher in the NSO group (0.36 \pm 1.0 vs. $-0.55 \pm 1.2 ; p<0.001$ ) (both scores correspond to the fair quality of life). In both groups, the average $M-A Q o L$ questionnaire score significantly improved, from $0.02 \pm 1.2$ points (fair quality of life) at baseline to $1.0 \pm 1.2$ (good quality of life) after 5 years $(p<0.001)$. After 5 years, all scores, except the social activity score $(p=0.08)$, significantly improved. After 5 years, the average M-AQoL questionnaire scores remained higher in the NSO group, but the difference was not significant $(1.1 \pm 1.1$ vs. 0.48 $\pm 1.0 ; p=0.066$ ).

The mean BAROS score after 5 years was significantly higher in the NSO patients $(3.44 \pm 2.1$ vs. 2.23 \pm 2.6 ; $p=0.038$ ).

\section{Discussion}

Choosing the ideal surgical strategy for the treatment of SO patients is still a subject of debate, due to the unique perioperative technical difficulties, increased surgical risk, inferior weight loss results $[5,7]$, and resistance to behavioral change [14].

Many bariatric/metabolic operations, including LAGB [5-7], sleeve gastrectomy [15, 16], Roux-en-Y gastric bypass [17, 18], and biliopancreatic diversion with duodenal switch [19], have been shown to be effective; however, with the increasing complexity of the procedure, morbidity and mortality also rise [20,21].

Although LAGB is not the most effective bariatric procedure concerning weight loss $[18,19]$, it is the least invasive, and also the safest bariatric operation regarding mortality and morbidity in the early postoperative period [20-22]. Therefore, its application to high-risk SO patients seems rational.

In a prospective study, Mittermair et al. reported that the \%EWL 4 years following LAGB in 60 SO pa- 
tients was $60.4 \%$, and the overall complication rate was $26.7 \%$ (4 pouch dilations, 5 band migrations, and 7 band leakages) [6].

Torchia et al. prospectively estimated the efficacy of LapBand in 95 SO patients. They found that \%EWL after $1,2,3$, and 4 years was $53.6 \%, 69.7 \%, 81.3 \%$, and $82.1 \%$, respectively [7].

Fielding et al. estimated the efficacy of LAGB in 76 super-SO patients $\left(\mathrm{BMI}>60 \mathrm{~kg} / \mathrm{m}^{2}\right)$. The $\% \mathrm{EWL}$ after 1,3 , and 5 years was $46.6 \%, 56.5 \%$, and $61.4 \%$, respectively. The authors concluded that LAGB is a safe and relatively simple procedure, which can lead to excellent weight loss results in SO patients [5].

In contrast, Arapis et al. performed a study involving 186 SO patients who underwent LAGB. The $\%$ EWL after 4, 8, and 10 years was 38.3\%, 41.1\%, and $37.9 \%$, respectively. Moreover, during the 9 -year follow-up period, $46.8 \%$ of patients experienced major complications that resulted in band removal. Therefore, the authors concluded LAGB was not an appropriate bariatric approach for SO patients [8].

In our analysis, the mean \%EWL, 5 years after LAGB, was $47.3 \%$. The NSO patients demonstrated better \%EWL (50.4\% vs. 38.8\%), but the difference was not statistically significant $(p=0.072)$. However, there were significantly more NSO patients who reached $\mathrm{EWL}>50 \%$ (46.6\% vs. $27.2 \% ; p=0.045)$. A total of 7 (17.9\%) SO patients experienced longterm complications, which resulted in 3 (7.6\%) band removals during the 5-year period. Moreover, we found no statistically significant differences between SO and NSO patients regarding postoperative complications and quality of life.

The strengths of our study consist of its prospective fashion and 5-year follow-up rate of $87.3 \%$. Although this study was limited by its single-center design, and the relatively low sample size, our results add evidence for the safety and efficacy of LAGB application in SO patients.

\section{Conclusions}

This study suggests that LAGB can lead to substantial and long-lasting weight loss, and a significant improvement in obesity-related comorbidities after 5 years in both NSO and SO patients. Our study found that SO patients demonstrate inferior weight loss results, and lower overall BAROS scores; thus we do not support the primary use of LAGB as an effective procedure in $\mathrm{SO}$ patients.

\section{Conflict of interest}

The authors declare no conflict of interest.

\section{References}

1. Angrisani L, Santonicola A, Iovino P, et al. Bariatric surgery worldwide 2013. Obes Surg 2015; 25: 1822-32.

2. Kowalewski PK, Olszewski R, Kwiatkowski AP, Paśnik K. Revisional bariatric surgery after failed laparoscopic adjustable gastric banding - a single-center, long-term retrospective study. Videosurgery Miniinv 2017; 12: 32-6.

3. Angrisani L, Di Lorenzo N, Favretti F, et al. The Italian Group for LAP-BAND: predictive value of initial body mass index for weight loss after 5 years of follow-up. Surg Endosc 2004; 18 : 1524-7.

4. Chevallier JMM, Paita M, Rodde-Dunet MHH, et al. Predictive factors of outcome after gastric banding: a nationwide survey on the role of center activity and patients' behavior. Ann Surg 2007; 246: 1034-9.

5. Fielding GA. Laparoscopic adjustable gastric banding for massive superobesity ( $>60$ body mass index $\mathrm{kg} / \mathrm{m} 2$ ). Surg Endosc 2003; 17: 1541-5.

6. Mittermair RP, Aigner F, Nehoda H. Results and complications after laparoscopic adjustable gastric banding in super-obese patients, using the Swedish band. Obes Surg 2004; 14: 1327-30.

7. Torchia F, Mancuso V, Civitelli S, et al. LapBand System in super-superobese patients (>60 kg/m(2)): 4-year results. Obes Surg 2009; 19: 1211-5.

8. Arapis K, Chosidow D, Lehmann M, et al. Long-term results of adjustable gastric banding in a cohort of 186 super-obese patients with a BMI $\geq 50$ kg/m2. J Visc Surg 2012; 149: e143-52.

9. Juodeikis Ž, Abalikšta T, Brimienè V, Brimas G. Laparoscopic adjustable gastric banding: a prospective randomized clinical trial comparing 5-year results of two different bands in $103 \mathrm{pa}$ tients. Obes Surg 2016; 27: 1024-30.

10. Oria HE, Moorehead MK. Bariatric analysis and reporting outcome system (BAROS). Obes Surg 1998; 8: 487-99.

11. Report of the Expert Committee on the Diagnosis and Classification of Diabetes Mellitus. Diabetes Care 2003; 26 (Suppl. 1): S5-20.

12. McKenney JM. Update on the National Cholesterol Education Program Adult Treatment Panel III guidelines: getting to goal. Pharmacotherapy 2003; 23: 26S-33S.

13. Moorehead MK, Ardelt-Gattinger E, Lechner H, Oria HE. The validation of the Moorehead-Ardelt Quality of Life Questionnaire II. Obes Surg 2003; 13: 684-92.

14. Engström M, Forsberg A, Søvik TT, et al. Perception of control over eating after bariatric surgery for super-obesity: a 2-year follow-up study. Obes Surg 2015; 25: 1086-93.

15. Eid GM, Brethauer S, Mattar SG, et al. Laparoscopic sleeve gastrectomy for super obese patients: forty-eight percent excess weight loss after 6 to 8 years with 93\% follow-up. Ann Surg 2012; 256: 262-5.

16. Rawlins L, Rawlins MP, Brown CC, Schumacher DL. Sleeve gastrectomy: 5-year outcomes of a single institution. Surg Obes Relat Dis 2013; 9: 21-5. 
17. Thereaux J, Czernichow S, Corigliano N, et al. Five-year outcomes of gastric bypass for super-super-obesity (BMI $\geq 60 \mathrm{~kg}$ ) m2): a case matched study. Surg Obes Relat Dis 2015; 11: 32-7.

18. Giordano S, Tolonen P, Victorzon M. Laparoscopic Roux-en-Y gastric bypass versus laparoscopic adjustable gastric banding in the super-obese: peri-operative and early outcomes. Scand J Surg 2015; 104: 5-9.

19. Dolan K, Hatzifotis M, Newbury L, Fielding G. A comparison of laparoscopic adjustable gastric banding and biliopancreatic diversion in superobesity. Obes Surg 2004; 14: 165-9.

20. Buchwald H, Estok R, Fahrbach K, et al. Trends in mortality in bariatric surgery: a systematic review and meta-analysis. Surgery 2007; 142: 621-32; discussion 632-5.

21. Morino M, Toppino M, Forestieri P, et al. Mortality after bariatric surgery: analysis of 13,871 morbidly obese patients from a national registry. Ann Surg 2007; 246: 1002-7; discussion 1007-9.

22. Sertkaya M, Emre A, Yazar FM, Bülbüloğlu E. Diagnosis and management of early gastric band slip after laparoscopic adjustable gastric banding. Videosurgery Miniinv 2016; 11: 121-5.

Received: 24.03.2018, accepted: 6.06.2018. 